\title{
Medicalização da infância e psicanálise: o caso TDAH
}

\section{Childhood medicalization and psychoanalysis: the ADHD case}

\author{
Ana Karina Barbosa Moura ${ }^{1}$, Bruna D’Arezzo Pessente Gallucci², \\ Maria Fernanda Assis Ribas ${ }^{3}$, Érico Bruno Viana Campos ${ }^{4}$
}

Resumo

O presente ensaio teórico, em caráter de revisão narrativa de literatura, visa caracterizar o escopo das discussões sobre a medicalização da infância no campo da atenção à saúde em transtornos de déficit de atenção e hiperatividade no âmbito da abordagem psicanalítica. Parte da caracterização do fenômeno da medicalização do social e da infância em articulação com os desenvolvimentos na psicopatologia psiquiátrica a partir da consolidação do modelo sindrômico e organicista baseado em evidências epidemiológicas para tecer um contraponto crítico a partir da psicopatologia psicanalítica. Apresenta as principais hipóteses sobre a especificidade desse tipo de sintomatologia, indicando um mecanismo de falha de simbolização que não está necessariamente ligado a uma estrutura clínica específica. Discute também a incidência de fatores socioculturais da atualidade na produção e sustentação desse tipo de saída para os conflitos emocionais das crianças. Conclui pela reafirmação de uma posição de singularização e colocação em perspectiva histórica o sofrimento do sujeito como condição para o trabalho de escuta desses casos.

Palavras-chave: Psicopatologia. Psicanálise. Transtorno de déficit de atenção e hiperatividade. Revisão de literatura. Infância.

\begin{abstract}
This theoretical essay, as a narrative literature review, aims to characterize, within a psychoanalytic approach, the scope of the debate on childhood medicalization in the matter of attention deficit and hyperactivity disorders health. It begins defining social and childhood medicalization phenomena in conjunction with psychiatric psychopathology developments that arise from the syndromic and organicist model based on epidemiological evidence. The purpose is to weave a critical counterpoint from psychoanalytic psychopathology. It presents the main hypotheses about this kind of symptomatology, indicating a mechanism of symbolization failure that is not necessarily linked to a specific clinical structure. It also discusses the incidence of current socio-cultural factors in the production and support of this type of outcome for children's emotional conflicts. It concludes by reaffirming a position of singularization and putting into historical perspective the subject's suffering as a condition for listening to these cases.
\end{abstract}

Keywords: Psychopathology. Psychoanalysis. Attention deficit and hyperactivity disorder. Literature review. Childhood.

${ }^{1}$ Doutoranda em Psicologia na Universidade Estadual Paulista Júlio de Mesquita Filho (Unesp), São Paulo, Brasil.

${ }^{2}$ Graduação em Psicologia pela Universidade Estadual Paulista Júlio de Mesquita Filho (Unesp), Bauru, São Paulo, Brasil.

${ }_{3}$ Mestranda em Psicologia do Desenvolvimento e Aprendizagem na Unesp, Bauru, São Paulo, Brasil.

${ }^{4}$ Doutorado em Psicologia pela Universidade de São Paulo (USP), São Paulo, Brasil. Professor do Departamento de Psicologia da Faculdade de Ciências da Unesp, Bauru, São Paulo, Brasil. E-mail: ebcampos@fc.unesp.br 


\section{Introdução}

O uso de medicamentos vem se mostrando crescente, um aspecto preocupante para a área de saúde e para a sociedade em geral, que já começa a mobilizar-se para a questão do uso irracional de medicamentos e para a medicalização da vida (BRASIL, 2018). Nesse contexto, o uso de fármacos não raro é apresentado como proposta de melhoria para o desenvolvimento dos indivíduos, sendo introduzidos desde a infância (CUNHA; MELLO, 2017). Desde o início do século XXI houve um crescimento dos diagnósticos de transtornos psiquiátricos. Isso se deu por uma maior amplitude de aplicação dos critérios diagnósticos a parcelas da população antes desassistidas ou a âmbitos antes negligenciados, mas também pela própria modificação nos critérios diagnósticos nas últimas décadas, o que ampliou sobremaneira a prevalência de transtornos sem aumentar necessariamente o número de portadores. De qualquer modo, relatórios recentes de saúde pública revelam o aumento dramático de casos de depressão e ansiedade em escala mundial nas últimas décadas (BRASIL, 2018; PATEL et al., 2018).

Diante dessa perspectiva, tem-se o fato de que muitos aspectos e experiências da vida cotidiana, no âmbito das relações sociais, no âmbito do trabalho e da educação, este último principalmente na fase da infância, adquirem o estatuto de alguma doença ou distúrbio. Esse fenômeno, que de forma mais ampla, tem sido denominado de medicalização do social ou medicalização da vida e consiste em um processo político e cultural que transforma experiências de vida, reduzindo-as a uma racionalidade médica, tomando-as como expressão exclusiva do funcionamento anátomo-fisiológico do corpo e, como patologia, no sentido de disfunção e negatividade em relação a critérios objetivos de saúde (BIRMAN, 2007; ESPERANZA, 2011).

Diante desse quadro geral de medicalização ou psiquiatrização do social, tem se destacado o debate sobre as transformações no olhar sobre a infância que se efetivaram a partir do desdobramento pós-moderno dessas questões para o âmbito da educação, a chamada medicalização da infância (AZEVEDO, 2018; CARRIJO, 2014). Os fenômenos mais ilustrativos e paradigmáticos são as polêmicas em torno da pretensa epidemia de transtornos de déficit de atenção e hiperatividade (TDAH) - com estimativas de 5 a $10 \%$ de prevalência mundial (KAMERS, 2016; MOYSÉS, 2001) - e também da preocupação crescente com os transtornos globais do desenvolvimento, com destaque para o espectro do autismo (JERUSALINSKY, 2011). Estes fenômenos estão na interface entre a psicologia da educação e a psicopatologia na promoção de políticas públicas na educação e na saúde, tendo sido abordados sistematicamente no Brasil desde os anos 2000, envolvendo setores importantes profissionais e governamentais, com uma expressiva mobilização do Sistema de Conselhos de Psicologia, por meio de campanhas, como a "Não à medicalização da vida" em 2012, e produção de materiais bibliográficos de referência (CONSELHO REGIONAL DE PSICOLOGIA DE SÃO PAULO; GRUPO INTERINSTITUCIONAL DE QUEIXA ESCOLAR, 2015), além de mobilizações intersetoriais, como a criação do Fórum Sobre Medicalização da Infância e Sociedade em 2010.

A psicanálise brasileira e latino-americana não tem sido alheia a este movimento, tendo participado ativamente desse debate a partir de alguns de seus setores mais engajados na perspectiva da psicanálise aplicada e da clínica ampliada, ou seja, no resgate da aplicação da psicanálise aos fenômenos culturais e na ampliação e extensão da clínica e sua escuta para as instituições da saúde, educação e trabalho, no sentido de promover subsídios para a reflexão política sobre a sociedade (CAMPOS, 2010). Nessa perspectiva, há um destaque para a compreensão psicanalítica de sofrimento e de cura, como uma forma de resgate da singularidade e da historicidade do sujeito desejante em contraposição ao discurso psicopatológico organicista dominante (BOCCHI, 2014; CASTRO, 2014), mas também suas implicações sociopolíticas, na medida em 
que o ato analítico também se constitui como uma forma de ação e operação sobre o laço social, no sentido de resgate e promoção da condição de sujeito (ROSA, 2016). Particularmente no âmbito da infância, a abordagem psicanalítica contemporânea tem apontado não só uma reflexão crítica e mesmo resistente na manutenção de uma abordagem subjetiva, histórica e compreensiva sobre os problemas da infância, com destaque não só para a escuta clínica do sofrimento nessas condições, mas também para sua compreensão sociocultural mais ampla e também para as derivações que incidem sobre as políticas públicas e modelos de atenção à saúde, na contramão das tendências objetivas e organicistas dominantes (CARRIJO, 2014; CORIAT, 2011).

No entanto, apesar de bem estabelecidas na forma de eixos gerais de posicionamento, uma perspectiva mais sintética dessas discussões no âmbito das contribuições para uma visão sobre os reflexos para o desenvolvimento humano e a constituição do sujeito ainda é rara. Nesse sentido, a proposta deste ensaio teórico é caracterizar e discutir a medicalização na infância e suas repercussões no desenvolvimento da criança a partir de um olhar psicanalítico, considerando a constituição de sua subjetividade e as manifestações sintomatológicas presentes nas situações que envolvem o diagnóstico de TDAH.

\section{Da Medicalização na Infância}

Quando se aborda o tema da medicalização, é preciso primeiramente distinguir do mero uso ou abuso de terapia medicamentosa, ou seja, de questões de medicação, para pensar como a partir da massificação e banalização dessa conduta se opera uma transformação na lógica de relacionamento com a saúde e a doença, que se amplia e infiltra nas relações humanas e no contexto sociopolítico geral, o que consiste propriamente o fenômeno da medicalização. Em segundo lugar, é preciso demarcar que há duas dimensões do fenômeno da medicalização, que reportam também a modelos teórico-conceituais distintos com pesos diferenciados nos diversos setores em que a questão pode ser abordada. Há um sentido mais restrito e mais recente, ligado à ampliação da lógica do medicamento para o social, que surge na área da saúde a partir da década de 1970, e também um sentido mais amplo, que surge nas discussões na área de humanidades, ligado ao próprio movimento de constituição das instituições modernas de amparo social pautadas pelo poder e saber de ordem médica (CAMPOS, 2016). Essa segunda perspectiva está fundamentada no percurso de Michel Foucault sobre a instituição saúde na modernidade, do nascimento da clínica ao biopoder, que tem sido o principal quadro teórico-conceitual de referência para a discussão sobre a temática na abordagem psicanalítica (BIRMAN, 2007).

O termo específico "medicalização", aparece pela primeira vez com Illich na década de 1970, descrevendo o processo no qual problemas não médicos são definidos e tratados como problemas médicos, usualmente em termos de doenças e desordens de cunho fisiológico (CAMPOS, 2016). Podemos ressaltar que os termos "medicalizar" e "medicamentalizar" não constituem sinônimos, embora tenham origem etimológica semelhante e têm tido uso recorrente. O segundo aparece como desdobramento de uma das definições para o verbo medicar - tratar com medicamentos, e o termo "medicalizar", seu alcance semântico vai mais além do que apenas tratar quimioterapicamente. "Medicalizar" ou "tornar médico" implica mesmo em uma relação da medicina com as pessoas e doenças, na qual se desconsideram os saberes e competências provenientes da própria existência humana, em prol de uma regulação desses saberes advinda da ciência e da medicina (EDINGTON, 2012; TESSER, 2006).

Para Foucault (2008), uma das estratégias do exercício moderno do poder é, fundamentalmente, da ordem da normalização dos indivíduos, e, por conseguinte, das populações. Sendo assim, a palavra medicalização para este autor está ligada a uma medicina que, valendo-se do poder de seu discurso científico, toma a sociedade como objeto de higienização, disciplinando os corpos e 
ampliando de tal forma sua apropriação que chega à regulação de seus comportamentos: o biopoder, o poder sobre a vida das pessoas (FOUCAULT, 2001). Através dessa racionalidade científica que surge o binômio saúde-doença, passando este a ser objeto da medicina moderna, desarticulando o sujeito de seu sofrimento: os sintomas assumem destaque, sendo considerados os determinantes da doença, representando, assim, um sinal de patologia e não uma tentativa de resolução ou expressão (SANCHES; AMARANTE, 2014).

Contudo, as pessoas são submetidas ao controle e à regulação dos corpos a partir da justificativa de proteção à vida. Dessa maneira, a medicalização aparece como sendo este dispositivo de controle, visto que nada se pode sair da norma e do padrão preestabelecido. Sendo assim, a medicalização seria uma forma de controle social que normatiza, regula e administra diversos aspectos da vida humana; sob esta ótica, quanto mais o médico fizer parte de nossa vida, mais teremos a possibilidade de ter a vida "normalizada". Assim, medicalização é um fenômeno que evidencia o discurso da medicina, como aquele que possui o estatuto da "verdade". Podemos destacar que vai além do tratamento de enfermidade, pois há uma gama de ações muito mais diversificadas. Por exemplo, é o discurso médico que nos orienta sobre a maneira que devemos nos comportar nas mais diferentes áreas de nossas vidas: o que devemos ou não comer, quantas horas devemos ou não dormir, a quantidade de exercícios que devemos ou não praticar, os afetos que devemos ou não sentir, a maneira que a criança deve ou não se comportar; tudo isto com o escopo velado ou manifesto de nos inserir no campo da normalidade ou da patologia.

Com o público infantil, as explicações médicas para a medicalização são encontradas nas dificuldades de aprendizagem das crianças, transformando essas dificuldades em doenças. É crescente o encaminhamento de crianças aos serviços de saúde mental com demandas sociais, os diagnósticos aparecem na difusão e na banalização de siglas que nomeiam as crianças e os adolescentes a partir de conjuntos de sinais e comportamentos que são observados principalmente durante o processo de escolarização. Remetem os sujeitos a uma classificação identificatória, naquilo que um diagnóstico impõe e nas suas repercussões no cotidiano escolar. Deste lugar os sujeitos são, em geral, lançados a territórios fronteiriços que se colocam à disposição para diferentes estratégias de tratamento - reeducação psicopedagógica, terapia psicológica e fonoaudiológica - ainda que, no campo originário, prevaleça a estratégia medicamentosa (EDINGTON, 2012). O aumento de consumo de psicofármacos pela população infantil coloca as indústrias farmacêuticas no centro do cenário da medicalização (TESSER, 2006).

No âmbito da psicopatologia psiquiátrica, os denominados transtornos específicos do desenvolvimento das habilidades escolares e os transtornos hipercinéticos derivam de critérios diagnósticos elencados pelo CID 10 e pelo DSM V, e geralmente incidem naquelas crianças que não se adaptam ao cotidiano escolar e/ou doméstico. O próprio termo transtorno específico do desenvolvimento da habilidade escolar traz consigo a concepção de que quem não aprende e quem não desenvolve determinada habilidade é a criança, muitas vezes sem se levar em consideração as condições de ensino e educação. Isso porque apesar do sistema classificatório especificar que o diagnóstico se dê em condições ideais de prática educacional, o uso que se faz por vezes o desconsidera. $\mathrm{O}$ fator biológico existe e precisa ser levado em consideração, porém a crítica realizada não se refere ao método da medicina em si, mas à prática contemporânea que ocorre através desses manuais (CUNHA; MELLO, 2017; ESPERANZA, 2011). No caso das crianças, um comportamento inadequado em sala de aula passa a ser considerado um problema médico quando analisado exclusivamente sob a ótica de que os problemas de comportamento possuem origens essencialmente orgânicas ou bioquímicas, porque se trata de um distúrbio do neurodesenvolvimento. É importante ressaltar, novamente, que a questão não é tanto a compreensão da comunidade ou literatura médica sobre o fenômeno, que sustenta 
a sua causalidade multifatorial e complexa, mas a lógica discursiva que vem transcender o discurso médico e se configurar como uma ideologia permeando o senso comum das práticas sociais.

A medicalização diante das dificuldades de aprendizagem alimenta a crença de que as dificuldades estão no aluno e são consequências de uma doença. Esse fato movimenta vários encaminhamentos a especialistas feitos pelas escolas, e as crianças são submetidas a uma quantidade de exames e testes tantos quantos forem necessários até encontrar um suposto diagnóstico. Quando uma criança com sintoma de agitação é considerada exclusivamente da perspectiva de um distúrbio neurológico tem-se a redução de um fenômeno biopsicossocial, como o ensino, a um discurso médico. Do mesmo modo, tem-se a redução de um problema escolar a um problema clínico. É bem estabelecido na psicologia escolar o peso das interações sociais e das configurações institucionais na produção do fracasso escolar a partir da lógica da profecia autorrealizadora (PATTO, 2000). O rótulo diagnóstico, independente de seu embasamento médico, é uma variável importante nessas configurações na atualidade.

A criança vive em crescimento e desenvolvimento, sendo muito vulnerável às situações de violência que ocorrem em seu entorno social, seja na família, na escola ou na comunidade em que vive. Ela depende de proteção e orientação dos adultos, das instituições e das políticas públicas; assim, em vez de considerar que a criança está com seu psiquismo em estruturação, supõe-se que ela tenha um déficit neurológico. Comportamentos como timidez, agitação e tristeza são vistos como doenças, e nos casos de agitação, há uma tendência a considerar a criança como portadora de TDAH (SANCHES; AMARANTE, 2014). Os medicamentos têm sido apresentados à sociedade como soluções rápidas, que na realidade vêm apresentando consequências graves em razão da intoxicação resultante do uso abusivo.

Entre as consequências graves, pesquisas apontam para surtos psicóticos e maníacos em crianças, após o uso frequente dos estimulantes prescritos comumente para o tratamento de TDAH (CHERLAND; FITZPATRICK, 1999; DELBELLO, 2001). Em 2006, a FDA (Administração de Alimentos e Medicamentos dos EUA), emitiu relatório a respeito deste risco, pois "pacientes sem nenhum fator de risco identificável" de psicose, apresentaram quadros de alucinações visuais, "Nas crianças pequenas, a predominância de alucinações visuais e táteis envolvendo insetos, cobras e vermes é impressionante" (WHITAKER, 2017, p. 157).

O Brasil ocupa o segundo lugar de consumo de cloridrato de metilfenidato, estimulante comercializado como Ritalina, principalmente, para o tratamento de crianças diagnosticadas com TDAH, e, por conseguinte, o aumento dessa produção decorre de sua vinculação ao diagnóstico desse transtorno (CUNHA; MELLO, 2017; EDINGTON, 2012). Isso ilustra um dos efeitos da expansão da indústria farmacêutica e do setor de biotecnologia no peso da economia capitalista global. Apoiada nos avanços tecnológicos e científicos, por um lado, e na transição para o capitalismo pós-industrial e de serviços, por outro, a pós-modernidade propaga o consumo de medicamentos como a solução de todos os problemas de saúde que o ser humano pode ter. Os centros e laboratórios de pesquisa investem nos estudos sobre doenças, sendo estes grandemente financiados pela indústria farmacêutica para vender cada vez mais remédios para aliviar o mal-estar dos sujeitos (FREITAS; AMARANTE, 2017; SANCHES; AMARANTE, 2014). Dessa forma, compreendendo-se que o mercado capitalista visa uma economia lucrativa, onde tudo se torna objeto a ser vendido e consumido pelas pessoas, podese entender a força e o apelo do fenômeno da medicalização.

Contudo, a medicalização na infância, articulada à voracidade da indústria farmacêutica que disponibiliza e impõe o uso maciço de psicofármacos, frequentemente acontece em momento decisivo e singular para a constituição da subjetividade da criança, com efeitos não só sobre as crianças, mas sobre a própria concepção de infância. 


\section{Sobre a Educação e a Normatização}

O contexto educacional atual exerce papel de controle sobre o corpo e o comportamento das crianças. Enquanto uma instituição disciplinar, desde o fim do século XVIII, a escola, como pontuou Foucault (2008), dispunha do professor como vigilante de seus alunos; e os hierarquizava pelo saber; na contemporaneidade, no entanto, o mecanismo a movimentar a vigilância, são os comportamentos indesejáveis dos alunos, as classificações são agora de outra monta, não mais se relacionam com o saber, e sim com as diferenças individuais desses (CRUZ; OKAMOTO; FERRAZZA, 2016).

A fim de identificar crianças que divergiam da norma estabelecida, principalmente no âmbito escolar, ao longo da história humana foram sendo instituídas descrições, mensurações e normatizações. Nesse percurso, no enlaçamento entre medicina e pedagogia, os professores já se ocupavam inicialmente em investigar e treinar o corpo do aluno (FOUCAULT, 2008). Com as revoluções políticas francesa e industrial inglesa surgiram os ideais revolucionários de igualdade, liberdade e fraternidade, os quais se articularam à lógica do novo modo de produção capitalista. Nesse contexto, o movimento higienista debruça-se sobre a segregação dos "anormais", estabelecendose como prática social da alçada dos médicos (COUTO; CASTRO, 2015).

Existia a argumentação necessária à aparição de "clínicas de orientação infantil", onde equipes multiprofissionais responsabilizavamse por atender e observar crianças de conduta considerada estranha ou desorientada. Nesse período, inclusive, surgem as primeiras "escolas especiais" para crianças consideradas deficitárias. Também se dá atenção a questões relacionadas ao controle do desenvolvimento e do comportamento da criança, bem como à investigação e construção dos conceitos de normalidade e anormalidade, uma vez que, nesse novo contexto de surgimento da escola as diferenças e contrastes ficaram em evidência, e as condutas tidas como estranhas ou desorientadas passaram a ser alvo de investigação e encaminhamentos (COUTO; CASTRO, 2015).

Nesse contexto, foram construídas as teorias acerca do desenvolvimento infantil e da aprendizagem. Não obstante o seu caráter científico e suas finalidades objetivas, uma historiografia crítica dos saberes e práticas psicológicas apontam para sua emergência em resposta à necessidade de constituição de um saber disciplinar com finalidades normativas e adaptativas (FOUCAULT, 2001, 2008). Em suma, o parâmetro da organização do desenvolvimento normal constitui um saber externo e ideal do sujeito, construído a priori, incompatível com a perspectiva que pretende contemplar os elementos da subjetividade.

A educação se responsabilizaria pelo estabelecimento da norma e pela identificação dos desviantes, no intuito de moralizá-los e normalizá-los, e à psicologia e à psiquiatria caberia a responsabilidade de encontrar os modos para remediá-los. A forma de moldar aqueles que serão um dia adulto aos ideais estabelecidos socialmente, ou seja, a maneira de adequá-lo é através de um projeto claro para harmonizar a criança, aplicando-lhe uma modalidade nova de educação que pretende vigiar, disciplinar e segregar. A partir do momento em que a educação escolar se estabelece na dimensão do universal, institui-se também uma lógica normativa que estranha e exclui o que possa advir do singular de cada estudante (EDINGTON, 2012).

No que tange à compreensão dos sintomas e queixas escolares, considera-se a separação didática feita por Bercherie (2001) de três grandes períodos nesse contexto. O primeiro deles são as décadas iniciais do século XIX, nomeado período da medicina moral. Nele os saberes e práticas médicas incidiam sobre os comportamentos e não sobre o corpo. Os valores morais da época inscrevemse no corpo. Classifica-se como patologia moral comportamentos de desobediência às regras e aos consensos sociais, mantendo-se em consonância com o debate promovido pela psiquiatria inglesa da época, que visava à articulação entre a 'infância perigosa' e o 'defeito moral'. 
Já na segunda metade do século XIX, segundo grande período, havia o paradigma das "doenças do cérebro", no qual há articulação entre os fenômenos da medicalização e da judicialização de comportamentos infanto-juvenis. Aquilo que é considerado socialmente perigoso ou moralmente inadequado é alçado ao registro de doença ou de delinquência. Assim, foi estabelecida a conjunção entre o campo da saúde e da polícia, com fins de disciplinar os corpos, fato reeditado na atualidade, ao se buscar mais uma vez descrever e articular os chamados transtornos de comportamento ou conduta e a delinquência. Esse período seguia a lógica clínica tradicional advinda da época das doenças infectocontagiosas, a qual coincide com uma tendência social de segregação dos comportamentos desviantes daqueles estabelecidos como normais. Foi nesse contexto que Freud rompe com a lógica anatomofisiológica de que se há problema no corpo é necessário encontrar o órgão lesionado, passando à noção de que a gênese do problema das neuroses está no campo das representações psíquicas (CAMPOS, 2010), ou seja, de que os sintomas têm um sentido e se relacionam à história do paciente. Ao indicar esse território, o das representações psíquicas, a psicanálise inaugurava a abordagem do corpo como suporte do discurso, como nos mostra a linguagem do corpo (FOUCAULT, 2001).

Já a terceira etapa inicia-se na década de 30 do século XX e continua até hoje. Nela há uma apropriação das concepções psicanalíticas pela psiquiatria e daí para o senso comum, por um lado, e, por outro, o desenvolvimento de uma abordagem neurofisiológica e neuroendócrina recrudescendo a abordagem organicista em psiquiatria. Nessa perspectiva, passa-se a visar o déficit neuroquímico como fator explicativo.

Ainda assim, no que concerne à escolarização, tendo os discursos e as ações disciplinadoras já sido instaurados, empreendem-se técnicas classificatórias das crianças entre educáveis e ineducáveis, aptas e inaptas - categorias formuladas em relação a dois aspectos, cognitivos e morais, que levariam os escolares a classes regulares e especiais. Nesse período, é possível observar a prevalência do discurso médico higienista, ou seja, da preocupação com o sanitarismo e a prevenção das doenças no âmbito social, e, principalmente, no ambiente educacional. É nesse momento também que algumas vertentes da psicanálise vêm a compor um discurso e uma atuação de normatização da infância (COUTO; CASTRO, 2015).

Pode-se perceber que a pedagogia, quanto mais se especializa, mais convocava técnicos para dizer sobre as crianças. Teorias e técnicas são instituídas buscando estabelecer critérios de trabalho "pasteurizados", prescrições "precisas" sobre o "funcionamento" do aluno ou sobre o papel do professor. Enfim, constitui-se um discurso normativo que prima pela técnica e destitui qualquer espaço para o inesperado, um suposto saber que universaliza, fazendo perder a singularidade dos sujeitos.

\section{Da Universalização dos Manuais ao Enquadramento da Infância}

O Manual Diagnóstico e Estatístico em Psiquiatria (DSM), produzido pela Associação Americana de Psiquiatria (APA), referência na psiquiatria contemporânea, desde sua criação em 1952, já passou por diferentes revisões e globalizou-se. Suas influências não se restringem aos EUA: "Ao exportar seus conceitos e tratamentos dos transtornos mentais, aquele país igualmente exporta os processos de medicalização" (FREITAS; AMARANTE, 2017, p. 44).

Em sua primeira versão, a psicanálise era uma forte influência, e as doenças eram classificadas a partir da divisão proposta por Freud: (psicose, neurose e desordens de personalidade), assim como o DSM II em 1958. Em ambos, os diagnósticos não eram compreendidos de forma fechada, ou seja, quando tais sintomas equivalem à determinada doença ou síndrome; pelo contrário, não existiam limites demarcados entre diferentes síndromes, sintomas diferentes poderiam corresponder a uma mesma síndrome, ou vice-versa (RUSSO; VENÂNCIO, 2006). Nesse modelo de atuação, 
interessava mais desvendar os sintomas e suas relações com a história de vida de cada paciente, o que afastava a psiquiatria da racionalidade médica, pois o diagnóstico não estava determinado, fechado, este seria uma "construção" feita pelo médico.

É de fundamental relevância histórica lembrarmos que o advento dos medicamentos psicotrópicos se inicia em 1952, com a descoberta da clorpramazina. Logo vieram os antidepressivos, os ansiolíticos e o lítio usado para o que antes se conhecia como psicose maníaco-depressiva, hoje transtorno bipolar (AGUIAR, 2004; RUSSO; VENÂNCIO, 2006). A indústria farmacêutica, no entanto, necessitava de delimitações precisas entre o normal e o patológico, não só, para poder definir para quem estaria indicado o seu produto, como para desenvolver os testes exigidos para a aprovação da medicação. Em 1980, surge a terceira edição da classificação americana, o DSM III, que delimita o sano do doente, traz a descrição de cada transtorno, uma nomenclatura única e, principalmente, uma única lógica classificatória. O manual passa a ser essencialmente descritivo e de posição a-teórica, ou seja, se antes nas versões I e II, em cada descrição havia conceitos inferidos, sobretudo por clínicos psicanalíticos que possuíam concepções etiológicas para as perturbações mentais, nesta versão não se questionavam causas, agrupavam-se sintomas em determinados quadros diagnósticos (RUSSO; VENÂNCIO, 2006).

Os estudiosos da história da psiquiatria moderna estabelecem o DSM III como um marco, uma ruptura diante de um modelo diagnóstico que anteriormente baseava-se na fala de cada paciente e na construção médica diante deste relato.

O DSM III promoveu uma reviravolta no campo psiquiátrico, que se apresentou como uma salvação da profissão. Não se tratava apenas de disputas teóricas internas ou de progresso científico. Ele surge como efeito da presença cada vez maior de grandes corporações privadas no campo da psiquiatria, como a indústria farmacêutica e as grandes seguradoras de saúde. (AGUIAR, 2004, p. 42)
A necessidade de consenso nos diagnósticos, primordial para a indústria farmacêutica, é atingida e se mantém. Posteriormente, a Associação Americana de Psiquiatria lança a quarta edição (DSM IV) em 1994, e finalmente em 2013, a atual versão DSM V. A edição de 1994 manteve a ampliação nos números de quadros diagnósticos, e se propõe a atuar como suporte educativo nos ensinamentos de psicopatologia (AGUIAR, 2004; RUSSO; VENÂNCIO, 2006). O mesmo movimento é apontado nas apreciações das contribuições da edição de 2013, que levaram inclusive à instauração do movimento Stop DSM (CAPONI, 2014).

Com relação ao diagnóstico do TDAH, mesmo que de forma breve, algumas considerações se fazem importantes: trata-se de um diagnóstico essencialmente clínico, não há nenhum marcador biológico, nenhum exame capaz de detectá-lo, até porque, suas causas continuam, para a psiquiatria moderna, desconhecidas (LIMA, 2005; MOYSÉS; COLLARES, 1992). Embora tenha se configurado pela primeira vez em uma classificação psiquiátrica como um quadro diagnóstico passível de indicação medicamentosa só em 1957, os testes com o composto, metilfenidato, até hoje prescrito como a medicação para o tratamento, iniciaram-se em 1944, e já estavam liberados pela FDA para serem administrados para crianças desde 1961 (LIMA, 2005). Com o tempo, a ampliação desse discurso científico, que estabelece quadros descritivos e diagnósticos, chega aos comportamentos dos alunos, agora compreendidos como sintomas, propondo a reabilitação dos alunos supostamente identificados como desviantes, a partir de uma perspectiva objetiva, de uniformização e conformidade, seguindo critérios naturalizados e, portanto, isentos de qualquer determinação histórica, contextual e subjetiva. Assim, os comportamentos desviantes passam a carregar algum tipo de déficit químico e/ou neuronal como algo que oriente a inclusão de um psicofármaco já pesquisado e utilizado como tratamento primário de escolha (BIRMAN, 2007; MOYSÉS, 2001). 
Parece que a simples nomeação atua como um tranquilizador para a sociedade. Quase que um automatismo se instaura: ao nomear um diagnóstico é como se ele já estivesse em parte resolvido. O que, aliás, advém da ideia de que, ao se saber o diagnóstico, sabe-se o que fazer com ele (JERUSALINSKY, 2011). É como se o cuidado fosse sinônimo do diagnóstico: ao proferi-lo, ele já está recebendo o cuidado necessário. Daí é um passo para atitude de rotulação: passa-se a se relacionar como o outro apenas por meio de sua marca identitária patológica. Todavia, quando a intervenção se dá exclusivamente na dimensão medicalizante, $\mathrm{o}$ saber em jogo é o saber do Outro da ciência, aquele que nada quer considerar para além do organismo, em detrimento da subjetividade (LIMA, 2005). Estamos fadados, assim, a fixar a criança num lugar de objeto, impossibilitada de dizer algo que venha a se constituir como próprio, muitas vezes amansada e domada, contida em "camisas químicas" - versão contemporânea da camisa de força, outrora usada para refrear agitação violenta.

O progresso da nossa civilização tornase sinônimo de redução de sofrimento, mediante a tentativa de eliminação ou sedação de dores e sintomas e controle dos riscos e doenças crônicas. Assim, a dor, a doença e seus riscos começam a ser vistos primeiro como a condição dos homens a quem a corporação médica não concedeu $o$ benefício de sua caixa de ferramentas.

\section{A Psicanálise Diante do TDAH}

A Psicanálise concebida por Sigmund Freud (1856-1939), através de suas investigações e elaborações, desde a última década do século XIX à terceira do século XX, continua em constantes reformulações e admitindo variadas leituras (CAMPOS, 2010; DUNKER, 2011). Desde suas primeiras concepções de aparelho psíquico e de como a energia circula e se processa dentro deste, estabeleceu-se as bases para uma teorização a respeito da instauração do aparelho psíquico a partir de um ponto de vista energético (FREUD, 1995), assim como formulações a respeito das manifestações sintomatológicas a partir do conflito psíquico em diferentes psicopatologias (FREUD, 1996).

Ao investigar os sintomas de seus pacientes, Freud passa a concebê-los de uma forma completamente distinta da medicina, e, ao longo de suas reflexões, os compreende como uma expressão de conflito, uma mensagem do inconsciente e uma forma de satisfação pulsional (MAIA; MEDEIROS; FONTES, 2012). Dentro dessa perspectiva, a psicanálise continua a investigar a singularidade do sintoma de cada pessoa, principalmente em sua clínica com crianças, como Winnicott (2000, p. 169) alertava:

O psiquiatra infantil enxerga no sintoma uma organização de extrema complexidade, produzida e mantida graças ao seu valor. A criança precisa do sintoma devido a algum empecilho ocorrido em seu desenvolvimento emocional. [...] O psiquiatra, portanto, não é um 'curador' de sintomas'. Ele reconhece no sintoma um SOS que justifica uma investigação completa da história do desenvolvimento emocional da criança em relação ao seu ambiente e à cultura. $\mathrm{O}$ tratamento é direcionado à necessidade da criança de emitir um SOS.

Para a Psicanálise, o sintoma sempre será uma bússola, a direcionar o profissional para a verdade, a subjetividade de cada sujeito: "o sintoma não é [...] apenas um problema, mas uma solução, uma resposta, por vezes precária, para conflitos que constituem o próprio sujeito" (DUNKER, 2002, p. 13). Sendo o sintoma, portanto, parte do sujeito, e necessário à compreensão de sua subjetividade e estruturação psíquica, seu extermínio, seu silenciamento, por meio de uma medicação, representam um grande risco de não compreendermos o essencial para o alívio dos sofrimentos. Nesse sentido, a psicanálise defende que os sintomas necessitam de significação, portem ele um sentido inconsciente e/ou indicação de falha estrutural, como desenvolveremos a seguir, antes de serem eliminados mediante um psicofármaco.

No caso da infância, onde a estrutura psíquica está em construção, se faz necessário um 
cuidado ainda maior no manejo dos sintomas e da medicalização:

Nesse sentido, o sintoma é o que a criança possui de mais real e o verdadeiro ponto de enlaçamento da causa do desejo com o mais-gozar, ou seja, com o impossível de ser plenamente descrito e capturado pelas malhas da razão diagnóstica própria ao saber médico-científico. Cabe à psicanálise afirmar e sustentar, com a expressão sujeito-criança, o que, no saber da ciência e na sociedade, é reduzido a uma classificação muda. Em outras palavras, como o saber médico-científico pauta sua ação em um discurso homogeneizante e classificatório, a criança perde aí a chance de se dizer. (COUTO; CASTRO, 2015, p. 152)

Especificamente com relação aos comportamentos descritos e agrupados pela psiquiatria moderna como Transtorno de Déficit de Atenção e Hiperatividade (TDAH), debate-se dentro da comunidade psicanalítica se estes poderiam ser considerados pelos analistas como sintomas.

Quando se referiu a uma mensagem a ser decifrada e/ou a manifestação de um conflito, ou até mesmo a satisfação pulsional, Freud o fez, considerando uma estruturação psíquica já formada, constituída. Portanto, não haveria uma organização edípica constituída, definindo de forma mais fixa a personalidade. Daí a noção que em função disso também a transferência não se instituiria efetivamente, com restrições à análise infantil. Contudo, a instauração da técnica de análise infantil veio justamente no sentido de compreender a labilidade estrutural da condição subjetiva infantil e também nas formas específicas de transferência que se constituem a partir de suas condições. É assim que se entende nesse contexto de indefinição estrutural o sintoma como um apelo de cuidado e uma tentativa de resposta, mas não necessariamente da ordem de um retorno do recalcado.

Nesse sentido, Silvia Bleichmar (1993, 2005), sugere não haver estrutura o suficiente para os sintomas serem produzidos, tal como Freud os concebeu, ou seja, investimentos deslocados e condensados em substitutos simbólicos da ordem de representações de palavra. Nesses casos, haveria antes falhas no processo inicial de constituição do psiquismo e dos processos de simbolização, de forma que as energias circulariam à espera de significações que pudessem sustentá-las. A autora parte de concepções freudianas e algumas concepções de Laplanche, dentre elas a sua teoria da sedução generalizada, para discutir perturbações na instalação do aparelho psíquico, que ficaria impossibilitado de processar os estímulos externos; de organizá-los em representações de palavra, o que consequentemente desarticularia as aquisições iniciais da categoria tempo, espaço e lógica, essenciais para a organização pelo psiquismo da realidade externa. Pensando nessas estruturações, ou falta delas, é possível compreendermos por que as respostas destas crianças são na maioria das vezes sensóriomotoras, ou seja, excitações que regressivamente produzem falhas no âmbito da manutenção da atenção psíquica ou que se descarregam produzindo efeitos psicomotores hipercinéticos. Essas situações são denominadas pela autora de transtorno na constituição psíquica; ou seja, o transtorno diz respeito àquilo que nunca foi fixado ou recalcado, enquanto no sintoma, há um desejo recalcado que o eu nega para si mesmo. Nesse sentido, Bleichmar (2005, p. 11) propõe, apoiada em uma perspectiva de neogênese, que a intervenção analítica está para além de desvelar aquilo que já se encontra simbolizado e recalcado no paciente - sintoma - mas deve possibilitar o "[...] engendramento de novos modos de produção simbólica, que possibilitem a fundação e recomposição de falhas estruturais para o funcionamento psíquico [...]”".

Partindo da mesma posição geral, diferentes autores destacam particularidades dessa clínica com crianças que apresentam falhas estruturais. Assim, no que tange o manejo analítico, existiriam momentos em que prevalece a construção de um espaço psíquico: "possibilitando o pensamento, o registro de afetos e abranda-se a passagem ao ato" e uma segunda etapa em que o acento está colocado "sobre a interpretação de desejos e na construção de sequencias lógicas" (JANIN, 2007, p. 99, tradução nossa). 
Do mesmo modo entendem-se as particularidades transferenciais, que estão para além da capacidade do analista em compreender o sentido das palavras, pois não são enigmas o que circula por entre a dupla, mas a convocação do corpo do analista em si:

Com o sujeito do "transtorno", urge ficar "à sua disposição", de uma forma diferente daquela na qual basta dispormos de uma escuta atenta ao sentido das palavras. Toda a situação funciona como se ele fosse extraindo pedaços do nosso corpo e, na maioria das vezes, não podemos ter clareza quanto aos aspectos de nossos atos e/ ou palavras que produziram sobre ele certos efeitos. (ZIMMERMANN, 2007, p. 67)

A Psicanálise aborda a complexidade que circunda a constituição mental humana e, ao levar em conta os sofrimentos psíquicos do sujeito criança, não visa conclusões generalistas, até porque, tanto a história quanto a relação transferencial são completamente singulares e necessárias a qualquer tentativa de compreensão das manifestações dos comportamentos e/ ou sintomas infantis, assim como reflexões a respeito do contexto sociocultural que perpassa a formação da criança em seus vínculos familiares e sociais.

Janin (2011) destaca características de nossa sociedade, relacionadas ao medo da exclusão, por exemplo, que fatalmenteinfluenciamnossas relações com a aprendizagem. Essa já não simbolizaria as conexões com o prazer do conhecimento, mas seria a alternativa para entrada no mundo do trabalho. Assim, um fracasso no desempenho escolar poderia, antes de mais nada, significar uma futura exclusão do mundo de trabalho:

$\mathrm{Na}$ época atual, uma sociedade em que se idealiza o êxito fácil, o consumo, o poder da imagem, em que os mandos são do tipo: 'faça-o', em que há um excesso de informação, em que os ritmos são vertiginosos, em que o temido é a exclusão. Que lugar podem ocupar as crianças? Que projetos the propomos? (JANIN, 2011, p. 62, tradução nossa).
Sendo assim, em uma cultura do consumo e do excesso, não estaríamos produzindo crianças hiperativas?

A Psicanálise traz diferentes concepções e ampliações sobre as influências da cultura na formação das subjetividades. Pesquisas nesta área (BARBOSA, 2008) debatem as consequências das prescrições medicamentosas para sujeitos em desenvolvimento e apontam para resultados preocupantes:criançasqueatribuemconscientemente seus bons desempenhos exclusivamente à ingestão desses medicamentos, não só no aspecto acadêmico, como também no social.

\section{Considerações Finais}

O saber médico-psiquiátrico vigente em nossa sociedade compreende a infância de forma completamente recortada de sua porção subjetiva e singular. Assim, não há espaços, dentre as classificações utilizadas para contextualizações, independentes das relações que a criança possa construir no âmbito familiar e/ou escolar, pois seus comportamentos serão sempre possivelmente provenientes de um déficit neurofisiológico ou endocrinológico, em estudo.

Nos perguntamos: diante de uma sociedade imediatista, onde o excesso impera - sejam eles de informações, produtos a serem consumidos, diagnósticos e/ou remédios oferecer psicofármacos a sujeitos em processo de desenvolvimento, não seria um risco? Além disso: essa conduta não expressaria sobretudo um sintoma de nossa cultura? Nos referimos aqui à sintoma a partir de uma perspectiva estritamente psicanalítica. Nos indagamos se a medicalização em larga escala das crianças nos tempos atuais não estaria a serviço de silenciar os conflitos, negando-os?

$\mathrm{Se}$ compreendermos as manifestações comportamentais de crianças diagnosticadas pela medicina contemporânea como TDAH como falhas estruturais em seus psiquismos, tal como nos sugerem os autores acima apresentados, ao medicálas, não só negaríamos o que lhe são singulares, como prejudicaríamos estruturações mentais 
com mais recursos de simbolização. Não se trata de negar os avanços trazidos para a psiquiatria com os psicofármacos, nem a sua utilidade como recurso terapêutico. Questionamos a simplificação e reificação que eles podem trazer à abordagem da complexidade dos fenômenos subjetivos humanos e a compreensão do seu sofrimento. Assim, não é uma crítica à medicação como recurso terapêutico no contexto de uma abordagem multidisciplinar aos transtornos da infância, mas a redução do sofrimento e da condição de vida das crianças a um problema exclusivamente médico. Em outras palavras, critica-se a medicalização da infância e da vida em geral, ou seja, a redução que se faz dos sintomas a causas orgânicas, especialmente em um período de desenvolvimento físico e mental tão fundamental.

A Psicanálise desde sua invenção sustenta um saber que leva em conta os sofrimentos das pessoas, no que há de mais singular: sua história, seus laços sociais, seus vínculos e significados, além de sua condição de sujeito. Compreende assim o cuidar como a tarefa mais complexa e imprescindível à vida humana, além de mais urgente. Nesse sentido, é importante sua posição de resistência e também de criação na instauração e manutenção daquilo que é especificamente humano.

\section{Referências}

AGUIAR, A. A psiquiatria no divã: entre as ciências da vida e a medicalização da existência. Rio de Janeiro: Relume-Dumará, 2004.

AZEVEDO, L. J. C. Medicalização das infâncias. Psicologia USP, São Paulo, v. 29, n. 3, p. 451458, 2018.

BARBOSA, A. K. Era uma vez no encontro com crianças agitadas: o transtorno de déficit de atenção e hiperatividade diagnóstico e medicação. 2008. Dissertação (Mestrado em Psicologia) Faculdade de Ciências e Letras, Universidade Estadual Paulista, SP, Assis, 2008.

BERCHERIE, P. A clínica psiquiátrica da criança: estudo histórico. In: CIRINO, O. Psicanálise e psiquiatria com crianças: desenvolvimento ou estrutura. Belo Horizonte: Autêntica, 2001. p. 129-144.
BIRMAN, J. A biopolítica na genealogia da psicanálise: da salvação à cura. História, Ciências, Saúde, Manguinhos, v. 14, n. 2, p. 529-548, abr./ jun. 2007.

BLEICHMAR, S. Clínica psicanalítica $e$ neogênese. São Paulo: Annablume, 2005.

BLEICHMAR, S. Nas origens do sujeito psíquico: do mito à história. Porto Alegre: Artes Médicas, 1993.

BOCCHI, J. C. A toca do coelho da semiologia psiquiátrica: o problema das classificações dentro da classificação. In: CAMPOS, E. B. V.; CARRIJO, C. (org.). Psicanálise e questões da contemporaneidade. Curitiba: CRV: Cultura Acadêmica, 2014. v. 2, p. 11-20.

BRASIL. Ministério da Saúde. Secretaria de Ciência, Tecnologia e Insumos Estratégicos. Departamento de Assistência Farmacêutica e Insumos Estratégicos. Uso de medicamentos e medicalização da vida: recomendações e estratégias. Brasília: Ministério da Saúde, 2018.

CAMPOS, E. B. V. A posição singular da psicanálise no campo dos saberes e práticas psicológicas. In: FERREIRA, A. A. L. (org.). A pluralidade do campo psicológico: principais abordagens e objetos de estudo. Rio de Janeiro: Editora da UFRJ, 2010. p. 143-179.

CAMPOS, É. B. V. Uma perspectiva psicanalítica sobre as depressões na atualidade. Estudos Interdisciplinares em Psicologia, Londrina, v. 7, n. 2, p. 22-44, 2016.

CAPONI, S. O DSM-V como dispositivo de segurança. Physis: Revista de Saúde Coletiva, Rio de Janeiro, v. 24, n. 3, p. 741-763, 2014.

CARRIJO, C. A medicalização na infância como sintoma do mal-estar da pós-modernidade. In: CAMPOS, E. B. V.; CARRIJO, C. (org.). Psicanálise e questões da contemporaneidade. Curitiba: CRV: Cultura Acadêmica, 2014. v. 2, p. 21-30.

CASTRO, E. O. Psicanálise e saúde mental. In: CAMPOS, E. B. V.; CARRIJO, C. (org.). Psicanálise e questões da contemporaneidade. Curitiba: CRV: Cultura Acadêmica, 2014. v. 2, p. 115-120. 
CHERLAND, E.; FITZPATRICK, R. Psychotic side effects of psychostimulants: a 5-year review. Canadian Journal of Psychiatry, Ottawa, v. 44, n. 8, p. 811-3, 1999.

CONSELHO REGIONAL DE PSICOLOGIA DE SÃO PAULO; GRUPO INTERINSTITUCIONAL DE QUEIXA ESCOLAR (Org.). Medicalização de crianças e adolescentes: conflitos silenciados pela redução de questões sociais a doença de indivíduos. 2. ed. São Paulo: Casa do Psicólogo, 2005.

CORIAT, E. H. Os negros efeitos do DSM-IV. In: JERUSALINSKY, A.; FENDRIK, S. (org.). $O$ livro negro da psicopatologia contemporânea. 2 . ed. São Paulo: Via Lettera, 2011. p. 165-174.

COUTO, D. P.; CASTRO, J. E. Da higiene mental à higiene química: contribuições para um contraponto entre a criança tomada como objeto pelo higienismo e como sujeito de sua verdade pela psicanálise. Cadernos de Psicanálise, Rio de Janeiro, v. 37, n. 32, p. 135-133, jan./jun., 2015.

CRUZ, M. G. A.; OKAMOTO, M. Y.; FERRAZZA, D. A. O caso Transtorno do Déficit de Atenção e Hiperatividade (TDAH) e a medicalização da educação: uma análise a partir do relato de pais e professores. Interface: Comunicaçao, Saúde, Educação, Botucatu, v. 20, n. 58, p. 703-714, set. 2016.

CUNHA, J. A. P.; MELLO, L. M. L. Medicação/ medicalização na infância e suas possíveis consequências. Pretextos: Revista da Graduação em Psicologia da PUC Minas, Belo Horizonte, v. 2, n. 4, jul./dez., 2017.

DELBELlO, M. P.; SOUTUllO, C. A.; HENDRICKS, W.; NIEMEIER, R. T.; MCELROY, S. L.; STRAKOWSKI, S. M. Prior stimulant treatment in adolescents with bipolar disorder: association with age of onset. Bipolar Disorders, Pittsburgh, v. 3, n. 1, p. 53-71, 2001.

DUNKER, C. I. L. Estrutura e constituição da clínica psicanalítica: uma arqueologia das práticas de cura, psicoterapia e tratamento. São Paulo: AnnaBlume, 2011.

DUNKER, C. I. L. O cálculo neurótico do gozo. São Paulo: Escuta, 2002.
EDINGTON, V. L. T. A medicalização na infância: uma leitura psicanalítica. 2012. Dissertação (Mestrado em Psicologia) - Universidade Federal da Bahia, Salvador, 2012.

ESPERANZA, G. Medicalizar a vida. In: JERUSALINSKY, A.; FENDRIK, S. (org.). $O$ livro negro da psicopatologia contemporânea. 2. ed. São Paulo: Via Lettera, 2011. p. 53-61.

FOUCAULT, M. A ordem do discurso. São Paulo: Loyola, 2001.

FOUCAULT, M. Vigiar e punir: nascimento da prisão. 35. ed. Petrópolis: Vozes, 2008.

FREITAS, F.; AMARANTE, P. Medicalização em psiquiatria. 2. ed. Rio de Janeiro: Fiocruz, 2017.

FREUD, S. As neuropsicoses de defesa. In: FREUD, S. Edição standard das obras psicológicas completas de Sigmund Freud. Rio de Janeiro: Imago, 1996. v. 3.

FREUD, S. Projeto para uma psicologia. Rio de Janeiro: Imago, 1995.

JANIN, B. El sufrimiento psíquico em los ninõs: psicopatología infantil y constitución subjetiva. Buenos Aires: Centro de Publicaciones Educativas y Material Didáctico, 2011.

JANIN, B. Ninõs desatentos e hiperactivos, $A D D-$ $A D H D$ : reflexiones críticas acerca del transtorno por déficit de atención com o sin hiperactividad. 2. ed. Buenos Aires: Centro de Publicaciones Educativas y Material Didáctico, 2007.

JERUSALINSKY, A. Gotinhas e comprimidos para crianças sem história: uma psicopatologia pósmoderna para a infância. In: JERUSALINSKY, A.; FENDRIK, S. (org.). O livro negro da psicopatologia contemporânea. 2. ed. São Paulo: Via Lettera, 2011. p. 231-244.

KAMERS, M. A falsa epidemia do TDAH e os impasses no uso da metodologia DSM na infância. Estilos da Clínica, São Paulo, v. 21, n. 2, p. 516527, ago. 2016.

LIMA, R. C. Somos todos desatentos? O TDA/H e a construção das bioidentidades. Rio de Janeiro: Relume-Dumará, 2005. 
MAIA, A. B.; MEDEIROS, C. P.; FONTES, F. O conceito de sintoma na psicanálise: uma introdução. Estilos da Clínica, São Paulo, v. 17, n. 1, p. 44-61, 2012.

MOYSÉS, M. A. A institucionalização invisível: crianças-que-não-aprendem-na escola. São Paulo: Mercado de Letras, 2001.

MOYSÉS, M. A. A.; COLlARES, C. A. L. A história não contada dos distúrbios de aprendizagem. In: ALMEIDA, M. J. O sucesso escolar: um desafio pedagógico. Cadernos Cedes, Campinas, n. 28, p. 31-48, 1992.

PATEL, V.; SAXENA, S.; LUND, C.; THORNICROFT, G.; BAINGANA, F.; BOLTON, P.; HERRMAN, H. The Lancet Commission on global mental health and sustainable development. The Lancet, London, v. 392, n. 10157, p. 15531598, 2018.

PATTO, M. H. S. A produção do fracasso escolar: histórias de submissão e rebeldia. São Paulo: Casa do Psicólogo, 2000.

ROSA, M. D. A clínica psicanalítica em face da dimensão sociopolítica do sofrimento. São Paulo: Escuta/FAPESP, 2016.

RUSSO, J.; VENÂNCIO, A. T. A. Classificando as pessoas e suas perturbações: a "revolução terminológica" do DSM III. Revista Latinoamericana de Psicopatologia Fundamental, São Paulo, v. 9, n. 3, p. 460-483, set. 2016.

SANCHES, V. N. L.; AMARANTE, P. D. C. Estudo sobre o processo de medicalização de crianças no campo da saúde mental. Saúde em Debate, Rio de Janeiro, v. 38, n. 102, p. 506-514, jul./set. 2014.

TESSER, C. D. Medicalização social (I): o excessivo sucesso do epistemicídio moderno na saúde. Interface: Comunicação, Saúde, Educação, Botucatu, v. 10, n. 19, p. 61-76, jan./jun. 2006.

WHITAKER, R. Anatomia de uma epidemia: pílulas mágicas, drogas psiquiátricas e o aumento assombroso da doença mental. Rio de Janeiro: Fiocruz, 2017.

WINNICOTT, D. W. Tolerância ao sintoma em pediatria: relato de um caso. In: WINNICOTT, D. W. Da pediatria à psicanálise: obras escolhidas. Rio de Janeiro: Editora Imago, 2000. p.168-188.
ZIMMERMANN, V. B. O "Transtorno" na constituição psíquica e suas implicações na clínica com crianças. Boletim Formação em Psicanálise, São Paulo, ano 15, v. 15, p. 57-70, 2007. Edição especial. 